\title{
Comparison of Various Plastics Wastes Using X-ray Fluorescence
}

\author{
Faten Adel Ismael Chaqmaqchee*, Amera Ghareeb Baker, Najeba Farhad Salih
}

Department of Physics, Faculty of Science and Health, Koya University, Koy Sanjaq, Iraq

Email address:

faten.chaqmaqchee@koyauniversity.org (F. A. I. Chaqmaqchee), amera.baker@koyauniversity.org (A. G. Baker), najeba.farhad@koyauniversity.org (N.F. Salih)

${ }^{*}$ Corresponding author

\section{To cite this article:}

Faten Adel Ismael Chaqmaqchee, Amera Ghareeb Baker, Najeba Farhad Salih. Comparison of Various Plastics Wastes Using X-ray Fluorescence. American Journal of Materials Synthesis and Processing. Vol. 5, No. 2, 2017, pp. 24-27. doi: 10.11648/j.ajmsp.20170202.12

Received: March 14, 2017; Accepted: April 1, 2017; Published: April 24, 2017

\begin{abstract}
Plastics production is increased recently due to their various applications such as construction, electronic, packaging and others. The rising in plastics demand lead to developed of recycling and energy recovery method to control plastic wastes. Recycling process is needs to be arranged according to resins, colors and transparency of all plastics. Energy dispersive X-ray fluorescence (EDXRF) was developed for the determination of the chemical composition in different plastics materials (with resin identification code) of PETE (1) or PET (01), HDPE (2) or PE-HD (02), V (3) or PVC (03), LDPE (4) or PE-LD, PP (5) or PP (06), PS (6) or PS (06) and Others (7) or O (07). XRF was measured elements such as Si, S, Cl, Fr, Ca, $\mathrm{Ti}, \mathrm{V}, \mathrm{Fe}, \mathrm{Cu}, \mathrm{Zn}, \mathrm{As}, \mathrm{Kr}, \mathrm{Zr}, \mathrm{Nb}, \mathrm{Mo}$ and $\mathrm{Nb}$ in both $\mathrm{k}_{\alpha}$ and $\mathrm{k}_{\beta}$ lines, where PP with high percentage in both PET and PVC plastics, which is highly hazardous. In addition, chemical compositions in percentages were detected for various plastics materials.
\end{abstract}

Keywords: Plastics, XRF, Energy, Quantitative Analysis, Elements

\section{Introduction}

Plastics are as one of the greatest invention in the world [1], which can be produced from petroleum, natural gas, or renewable electricity [2]. They are responsible for changing quality of life through the developing of materials. These materials have variety applications due to their lightweight, high strength, design flexibility for any shape and their low cost [3]. Over the last 10 years, global production of plastics have been increased dramatically due to increasing demand in developing country as in Asia, Africa and South America [4], where China is the largest plastics producer in the world. The Europe plastics industry also expects expansion in global require [5]. Today, the person consumes a lot of plastic every year, mostly in the form of packaging materials and household parts. The growing waste is also become a big environmental issue in the world. In order to reduce plastic disposal to the landfill, recycling process is considered to reduce some amount of plastic waste. It is very important for plastics to be clean and then separated for recycling or energy demand including solar energy wind power, geothermal and hydropower technology [6].

In this paper, we used plastics waste of wide range of materials including polyethylene terephthalate (PET) or (PETE) [7], high-density polyethylene (HDPE) [8] and lowdensity polyethylene (LDPE) [9], polystyrene (PS) [10], polyvinylchloride (PVC) or (V) [7], polypropylene (PP) [8], and others plastics including acrylic, acrylonitrile butadience styrence, fibreglass, nylon, polycarbonate and polylactic acid (Other) or (O) [11]. LDPE, HDPE, and PP are the most type of thermoplastic used throughout the world for many applications such as bags, toys, containers, pipes (LDPE), housewares, industrial wrappings and film, gas pipes (HDPE), film, battery cases, automotive parts, electrical components (PP). In addition, polymers as polyethylene in contrast to condensation polymers as polyethylene terephthalate (PET) cannot be easily recycled using simple chemical methods [12], but the plastics can be recycled using either mechanical technique or chemical/feedstock recycling $[13,14]$. Therefore, the more reliable method has been used 
to reduce some amount of plastic waste.

Plastics contain different chemicals that are added to a polymer to improve manufacturing and materials performance such as durability, flexibility, longevity and aesthetics. Some of additives are highly hazardous as in PVC used on wire and cable, which contain lead and some end uses of polypropylene and polyethylene [15]. By comparing the plastics with other materials, the recycling of plastics can be used to identify and characterize of different collected plastics. There are various techniques used to determine the plastics type such as chemical analysis and infrared spectroscopy [16]. These techniques are less useful when looking for additives in the plastics. X-ray fluorescence (XRF) is evaluated as a method to determine the plastics types, where it used to determine chemical elements.

\section{Material and Method}

Plastics materials have been obtained from used personal plastics food, milk and water bottles and cosmetics containers. For the analysis, the plastic samples were cut into circular shape at diameter of around $3.5 \mathrm{~cm}$. The elemental concentration and their emitted energies for seven various plastics were determined using energy dispersive X-ray fluorescence (EDXRF). All measurements were carried out under vacuum, using a Rigaku NEX CG with $\mathrm{RX} 9, \mathrm{Mo}, \mathrm{Cu}$ and $\mathrm{Al}$ targets. Chemical elements of $\mathrm{Si}, \mathrm{S}, \mathrm{Cl}, \mathrm{Fr}, \mathrm{Ca}, \mathrm{Ti}, \mathrm{V}$, $\mathrm{Fe}, \mathrm{Cu}, \mathrm{Zn}, \mathrm{As}, \mathrm{Kr}, \mathrm{Zr}, \mathrm{Nb}$, and $\mathrm{Mo}$ were detected with plastics. The EDXRF $\mathrm{K}_{\alpha}$ and $\mathrm{K}_{\beta}$ lines intensities were measured for almost all plastics elements, in which the applied voltage increased in general with the required lines energies. The X-ray measuring time was only $200 \mathrm{~s}$ for the $\mathrm{Al}$ target and $100 \mathrm{~s}$ for other targets.

In this study, X-rays from the X-ray tube pass through an optional filter on their way to the plastics sample. The sample placed in the chamber and measured by $20 \mathrm{~mm}$ diaphragm in vacuum. The X-rays then travel from the sample to the detector, which is cooled electrically. The signal is then processed by electronics and sent to a computer program, where the chemical compositions and intensity versus energy is measured, as shown in Figure 1.

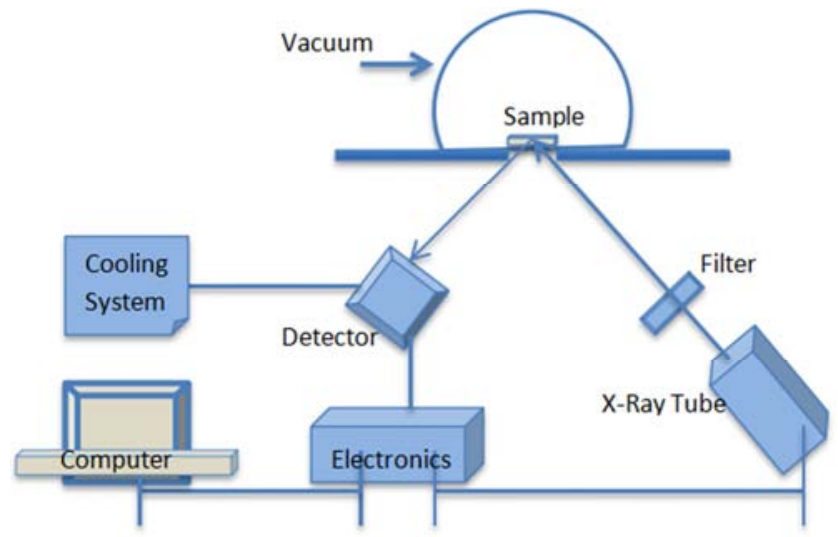

Figure 1. Schematic of a typical energy dispersive X-ray fluorescence EDXRF Spectrometer.

\section{Results and Discussion}

Rigaku NEX CG X-ray fluorescence (XRF) spectrometer analyses were used to determine elements using six plastics samples of PET, HDPE, PVC, LDPE, PP, PS and Others, numbered by $1,2,3,4,5,6$ and 7 , respectively. When these samples are irradiated with $\mathrm{X}$-rays, the intensity as a function of energy can be calculated over the energy range 1-20 keV at the same computing conditions. Figure 2 shows the peaks in the ranges of $1.74,2.32,2.63,2.86,3.69,4.03,4.52,4.96$, $6.4,8.01,8.81,10.56,12.63,15.77,16.83,17.48$, and 18.86 $\mathrm{keV}$ corresponding to Si- $\mathrm{k}_{\alpha}, \mathrm{S}-\mathrm{k}_{\alpha}, \mathrm{Cl}-\mathrm{k}_{\alpha}, \mathrm{Fr}-\mathrm{M}_{\beta}, \mathrm{Ca}-\mathrm{k}_{\alpha}, \mathrm{Ca}$ $\mathrm{k}_{\beta}$, Ti- $\mathrm{k}_{\alpha}, \mathrm{V}-\mathrm{k}_{\alpha}$, Fe- $\mathrm{k}_{\alpha}, \mathrm{Cu}-\mathrm{k}_{\alpha}, \mathrm{Zn}-\mathrm{k}_{\alpha}$, As- $\mathrm{k}_{\alpha}, \mathrm{Kr}-\mathrm{k}_{\alpha}, \mathrm{Zr}-\mathrm{k}_{\alpha}$, $\mathrm{Nb}-\mathrm{k}_{\alpha}, \mathrm{Mo}-\mathrm{k}_{\alpha}, \mathrm{Nb}-\mathrm{k}_{\beta}$ lines. It shows from figure that the intensity of Ti-k $\mathrm{k}_{\alpha}$ for HDPE sample has higher intensity than the other plastics samples, while the intensity of As- $\mathrm{k}_{\alpha}, \mathrm{Kr}$ $\mathrm{k}_{\alpha}$ and $\mathrm{Zr}-\mathrm{k}_{\alpha}$ have lower intensity or almost negligible intensity.

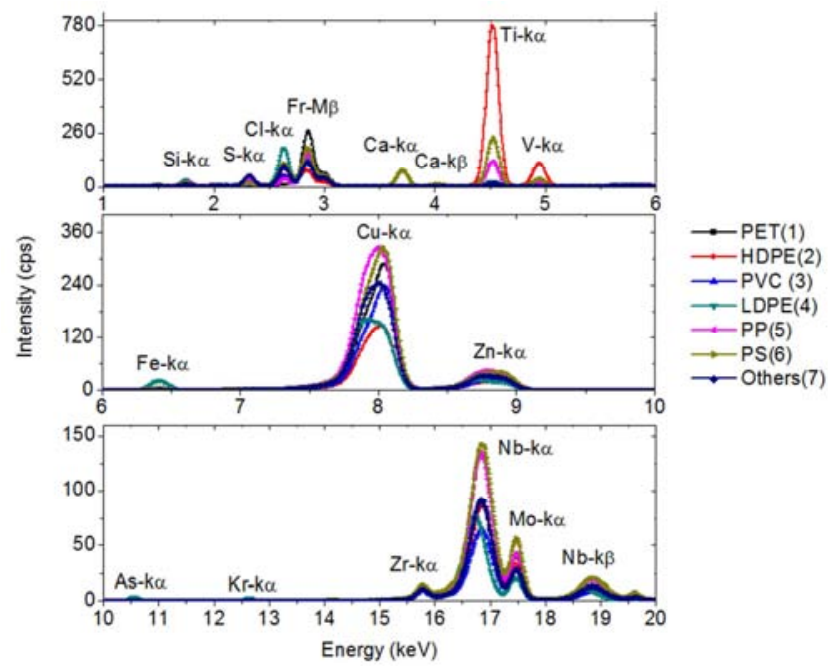

Figure 2. Intensity versus energy for various plastics of PET, HDPE, PVC, $L D P E, P P, P S$ and Others calculated over the energy range from 1 to 20 $\mathrm{KeV}$ using XRF with RX9, Mo, Cu and Al targets.

Furthermore, the chemical compositions for plastics of PET (1), HDPE (2), PVC (3), LDPE (4), PP (5), PS (6) and Others (7) have detected by the XRF. As shown in Table 1, the results are given as a relative mass concentration $\%$ of the elements contained in seven types of plastic samples. PP was selected as a fixed value from computer program. The $\%$ concentration of propene PP appears to be high in almost all the samples. PP has a good chemical and heat resistance and applications include flowerpot, office folders, car bumpers, pails, carpets and storage boxes [17]. PP is about 100\% in both PET and PVC plastics, which is highly hazardous if daily used. PET has great choice for various food products, mainly beverages such as mineral water, soft drink bottle and fruit juice containers [18], while applications of PVC has include wire and cable insulation, window frames, boots, food foil, medical devices, blood bags, automotive interiors, packaging, credit cards and synthetic leather [15].

The total percentages for the seven samples were less and more than $100 \%$ due to the statistical errors during 
measurement. Element of Ti is appear with high percentage at about 1.67, 0.255 and 0.612 in HDPE, PP and PS, respectively, which is in good agreement with Figure 2, that $\mathrm{Si}$ is detected with high intensity. HDPE, PP and PS. Plastics coded 1, 2, 3, 4, 5, 6 and 7 have high concentration of Si at around $0.0075,0.0182,0.0068,0.0567,0.0335,0.0363$ and
0.0175 , respectively. In addition, low concentrations at about 0.0001 were appeared in $\mathrm{Mn}, \mathrm{Cu}, \mathrm{Hf}$ and $\mathrm{Zn}$ for PET and PVC. Elements of (Br, Nb), (Hf, As, Rb), (Hf) and (Hf, Tb) appear also with very low concentration in HDPE, LDPE, PS and Others, respectively.

Table 1. XRF measurements for elements of Plastics (as percentages), where the totals are more than 100\% due to the statistical errors.

\begin{tabular}{|c|c|c|c|c|c|c|c|c|}
\hline \multirow{2}{*}{ No. } & \multirow{2}{*}{ Elements } & \multicolumn{7}{|c|}{ Concentration \% } \\
\hline & & PET (1) & HDPE (2) & PVC (3) & LDPE (4) & PP (5) & PS (6) & Others (7) \\
\hline 1 & PP & 100 & 98.2 & 100 & 99.8 & 99.6 & 98.7 & 99.7 \\
\hline 2 & $\mathrm{Si}$ & 0.0075 & 0.0182 & 0.0068 & 0.0567 & 0.0335 & 0.0363 & 0.0175 \\
\hline 3 & $\mathrm{Sb}$ & 0.004 & 0.0009 & 0.0028 & -- & -- & -- & -- \\
\hline 4 & $\mathrm{Ca}$ & 0.0022 & -- & 0.0037 & 0.0081 & 0.0049 & 0.0391 & 0.0056 \\
\hline 5 & $\mathrm{Al}$ & 0.0021 & 0.0274 & 0.0020 & 0.0429 & 0.0153 & 0.0341 & 0.0139 \\
\hline 6 & $\mathrm{~S}$ & 0.0014 & 0.0068 & 0.0013 & 0.0105 & 0.0136 & 0.0050 & 0.0201 \\
\hline 7 & $\mathrm{Cl}$ & 0.0011 & 0.0117 & 0.0086 & 0.0363 & 0.0068 & 0.0222 & 0.0188 \\
\hline 8 & $\mathrm{P}$ & 0.0009 & 0.0075 & 0.0010 & 0.0007 & 0.0027 & -- & -- \\
\hline 9 & $\mathrm{Sn}$ & 0.0004 & -- & -- & 0.0005 & 0.0007 & 0.0008 & 0.0006 \\
\hline 10 & $\mathrm{Fe}$ & 0.0003 & 0.0005 & 0.0005 & 0.0045 & 0.0006 & 0.0014 & 0.0003 \\
\hline 11 & $\mathrm{Ti}$ & 0.0002 & 1.67 & 0.0004 & 0.0567 & 0.255 & 0.612 & 0.0221 \\
\hline 12 & $\mathrm{Mn}$ & 0.0001 & -- & -- & 0.0002 & -- & -- & -- \\
\hline 13 & $\mathrm{Cu}$ & 0.0001 & 0.0001 & 0.0001 & 0.0005 & 0.0036 & 0.0002 & 0.0003 \\
\hline 14 & $\mathrm{Hf}$ & 0.0001 & -- & 0.0001 & 0.0001 & - & 0.0001 & 0.0001 \\
\hline 15 & $\mathrm{Zn}$ & 0.0001 & 0.0007 & 0.0001 & 0.0005 & 0.0004 & 0.0056 & 0.0016 \\
\hline 16 & $\mathrm{Mg}$ & -- & 0.0167 & -- & -- & 0.0149 & -- & -- \\
\hline 17 & $\mathrm{Br}$ & -- & 0.0001 & -- & -- & -- & -- & -- \\
\hline 18 & $\mathrm{Nb}$ & -- & 0.0001 & -- & -- & -- & -- & -- \\
\hline 19 & $\mathrm{~K}$ & -- & -- & -- & 0.0162 & -- & -- & 0.0007 \\
\hline 20 & $\mathrm{~Pb}$ & -- & -- & -- & 0.0011 & -- & -- & -- \\
\hline 21 & $\mathrm{Cr}$ & -- & -- & -- & 0.0011 & -- & -- & -- \\
\hline 22 & $\mathrm{Cu}$ & -- & -- & -- & 0.0005 & -- & -- & -- \\
\hline 23 & As & -- & -- & -- & 0.0001 & -- & -- & -- \\
\hline 24 & $\mathrm{Rb}$ & -- & -- & -- & 0.0001 & -- & -- & -- \\
\hline 25 & $\mathrm{Na}$ & -- & -- & -- & -- & -- & 0.201 & 0.136 \\
\hline 26 & No & -- & -- & -- & -- & -- & 0.0003 & -- \\
\hline 27 & $\mathrm{Sr}$ & -- & -- & -- & -- & -- & 0.0001 & -- \\
\hline 28 & $\mathrm{Zr}$ & -- & -- & -- & -- & -- & 0.0219 & 0.0159 \\
\hline 29 & $\mathrm{~Tb}$ & -- & -- & -- & -- & -- & -- & 0.0001 \\
\hline 30 & $\mathrm{Co}$ & -- & -- & 0.0001 & -- & 0.0001 & -- & -- \\
\hline
\end{tabular}

\section{Conclusions}

In summary, we had compared a various plastics wastes of PET (1), HDPE (2), PVC (3), LDPE (4), PP (5), PS (6) and Others (7) using XRF. In almost all plastics samples, high concentrations of $\mathrm{Si}$ element were appeared, while with low percentage of $\mathrm{Mn}, \mathrm{Cu}, \mathrm{Hf}, \mathrm{Zn}, \mathrm{Br}, \mathrm{Nb}, \mathrm{As}, \mathrm{Rb}$, and $\mathrm{Tb}$ was detected in other plastics samples. Plastics present a $100 \%$ percentage of PP in both PET and PVC, which used daily life and it seems highly hazardous.

\section{References}

[1] R. C. Thompson, C. J. Moore, F. S. vom Saal, S. H. Swan, "Plastics, the environment and human health: current consensus and future trends," Philos. Trans R Soc B, vol. 364, pp. 2153-2166, 2009.

[2] F. de Clippel, M. Dusselier, R. Van Rompaey, P. Vanelderen, J. Dijkmans, E. Makshina, L. Giebeler, S. Oswald, G. V. Baron, J. F. Denayer, P. P. Pescarmona, P. A. Jacobs, B. F.
Sels, "Fast and selective sugar conversion to alkyl lactate and lactic acid with bifunctional carbon-silica catalysts," J Am Chem Soc, vol. 134, pp. 10089-10101, 2012.

[3] A. L. Andrady, M. A. Neal, "Applications and societal benefits of plastics,” Phil Trans R Soc, vol. 364, 1977-1984, B 2009.

[4] UNEP, Global Chemical Outlook e towards Sound Management of Chemicals, 2013.

[5] Association of Plastic Manufacturers Europe. An analysis of European plastics production, demand and waste data. Belgium: European Association of Plastics Recycling and Recovery Organisations, pp. 1-32, 2015.

[6] J. H Tibbetts, "Managing marine plastic pollution: policy initiatives to address wayward waste. Environ Health Perspect," vol. 123, pp. A90-A93, 2015.

[7] S. D. Anuar Sharuddin, F. Abnisa, W. M. Ashri Wan Daud, M. K. Aroua, "A review on pyrolysis of plastic wastes," Energy conversion and management, vol. 115, pp. 308-326, 2016.

[8] S. H. Jung, M. H. Cho, B. S. Kang, J. S. Kim, "Pyrolysis of a fraction of waste polypropylene and polyethylene for the recovery of BTX aromatics using a fluidized bed reactor," Fuel Process Technol, vol. 91, pp. 277-84, 2010. 
[9] P. T. Williams, E. A. Williams, "Fluidised bed pyrolysis of low density polyethylene to produce petrochemical feedstock," J Anal Appl Pyrol, vol. 51, pp. 107-261999.

[10] J. A. Onwudili, N. Insura, P. T. Williams, "Composition of products from the pyrolysis of polyethylene and polystyrene in a closed batch reactor: effects of temperature and residence time," J Anal Appl Pyrol, vol. 86, pp. 293-303, 2009.

[11] J. A. Ivair do Sul, M. F., "Costa The present and future of microplastic pollution in the marine environment. Environ Pollut," vol. 185, pp. 352-364, 2014.

[12] G. P. Karayannidis, D. S. Achilias, Chemical recycling of poly (ethylene terephthalate), Macromol. Mater. Eng., vol. 292, pp. 128-146, 2007.

[13] J. G. Poulakis, C. D. Papaspyrides, "Recycling of polypropylene by the dissolution/reprecipitation technique: I. A model study," Res. Conserv. Recycl., vol. 20, pp. 31-41, 1997.
[14] J. G. Poulakis, C. D. Papaspyrides, "The dissolution/reprecipitation technique applied on high-density polyethylene: I. Model recycling experiments," Adv. Polym. Techn., vol. 14 (3), pp. 237-242, 1995.

[15] British Plastics Federation. Polyvinyl chloride (PVC). London; 2015.

[16] A. Garton, "Infrared Spectroscopy of Polymer Blends, Composites and Surfaces", Hanser Publishers, New York, 1992 .

[17] P. A. Michael, "Plastic waste total in MSW," Society of the Plastic Industry, 2010.

[18] Ö. Çepelioguullar, A. E. Pütün, "Thermal and kinetic behaviors of biomass and plastic wastes in co-pyrolysis," Energy Convers Manage, vol. 75, pp. 263, 2013. 